\title{
Flash-Free Orthodontic Adhesive System Compared with the Conventional Direct Bonding Method
}

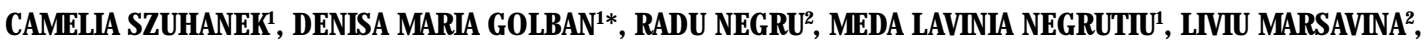
VIRGIL FLORIN DUMA ${ }^{2,3}$, COSMIN SINESCU1*, LILIANA POROJ AN ${ }^{1}$

'Victor Babes University of Medicine and Pharmacy, Faculty of Dental Medicine, 2 Eftimie Murgu Sq., 300041, Timisoara, Romania 2Polytechnic University of Timisoara,Faculty of Mechanical Engineering, 1 Mihai Viteazu Blvd., 300006 Timisoara, Romania 330M Optomechatronics Group,Aurel Vlaicu University of Arad, Faculty of Engineering, 77 Revolutiei Blvd., 310130 Arad, Romani

The latest technology in the field of orthodontic materials is represented by the Flash-Free Orthodontic Adhesive System. In the presentstudy this novel technique is compared with the conventional direct bonding method. Ten extracted human premolars were separated into two groups: in the Group 1, APC Flash-Free Adhesive Coated Appliance System (3M Unitek, Monrovia, CA, USA) was bonded, while in the control Group 2, Clarity Advanced braces (3M Unitek, Monrovia, CA, USA) were bonded using XT Adhesive Paste (3M Unitek, Monrovia, CA, USA) applied by the clinician on the bracket base. Bonding times were recorded for each sample. Shear bond strength (SBS) was recorded using Zwick Zoel Z005. After debonding, the adhesive remnant index (ARI) was established for both groups. Group 1 showed a mean bonding time of $21 \mathrm{~s}$, while Group 2 needed about $45 \mathrm{~s}$ for each bracket bonding. Both groups had clinically accepted SBS values, but the difference between them was significant (10.97 MPa versus 8.23 MPa). ARI scores were equal to 1 for most samples. In conclusion, reducing the time for bracket placing, APC Flash-Free Coated Appliance System showed a brackets bonding time reduced to half compared to the conventional technique. This aspect, combined with significantly higher SBS values, makes this novel system better than the classical one. For both groups, more than half of the adhesive remained on the bracket base, which facilitates cleaning after debonding.
\end{abstract}

Keywords: APC Flash-Free, orthodontic adhesive, bonding time, shear bond strength (SBS), adhesive remnant index.

In 1965, Newman revolutionised orthodontics by introducing the concept of direct bracket bonding[1]. Besides better aesthetics, this technique has several other advantages, including a lower risk of gum disease or cavities, time saving from tooth separation needed in band use, and no after-treatment spaces that come with the separation [2].

The adhesive system has to present high enough bond strength to resist the forces that are applied during both the treatment and daily activities, but low enough in order to allow for a debonding at the end of the treatment in a way that leaves the surface of the enamel intact. When a force is applied in a gingival direction, the bracket must resist to a minimum load of $6 \mathrm{MPa}$ [3].

After debonding, the remaining adhesive on the surface of the tooth or bracket base is another factor utilized for adhesive selection [4]. The first adhesive remnant index was established by Arrtun and Bergland, [5] with four grades in their classification, and was after modified by other authors[6]. Clinicians would prefer less residual resin considering as it is easier to clean, although a higher bonding strength could lead to difficulties in debonding and can induce enamel loss. In order to avoid enamel damage it is preferred to have fractures at the bracket-adhesive interface or inside the adhesive.

New materials and techniques are constantly introduced on the market. One of the latest and most innovative products is APC Flash-Free Adhesive Coated Appliance System (3M Unitek, Monrovia, CA, USA), which eliminates the need for excess material removal, saving time when bonding, but also having an increased bond strength [7].
The present paper examines the APC flash-free technology, comparing its performances with the classic direct bonding method, for which the adhesive is applied by the clinician on the bracket base. For consistency, all products utilized in the present study are manufactured by the same company.

\section{Experimental part \\ Material and methods}

Ten human premolars, extracted in the last six months and stored in physiological serum, were placed along their vertical axis in blocks of acrylic resin. After etching with $37 \%$ phosphoric acid for $30 \mathrm{~s}$, rinsing and drying, Transbond XT Light Cure Adhesive Primer (3M Unitek, Monrovia, CA, USA) was applied and cured.

The steps that followed, performed by the same clinician, were timed for every tooth. On half of the teeth analyzed (Group 1) APC Flash-Free Adhesive Coated Appliance System was applied. On the other half of the teeth analyzed (Group 2, control) Clarity Advanced braces (3M Unitek, Monrovia, CA, USA) were bonded using the conventional direct bonding technique, with Transbond XT Adhesive Paste (3M Unitek, Monrovia, CA, USA). For this latter group, after pressing each bracket on the tooth surface, the excess was removed with an explorer.

The shear bond strength (SBS) was tested for all the samples using a Zwick Zoel Z005 testing machine. The samples were mounted in the jug of the machine and the force was applied in a gingival-oclussal direction, parallel with the bracket axis, by tying a $0.25 \mathrm{~mm}$ wire around the bracket, with a speed of $1 \mathrm{~mm} / \mathrm{s}$ (fig. 1). 
After debonding, the brackets bases were photographed with a Canon 60D attached to a Zeiss OPMI1. On the obtained photographs, the following criteria were utilized in order to establish the adhesive remnant index: [5]

$0=$ the entire adhesive is left on the bracket base;

$1=$ more than half of the adhesive is left on the bracket base;

$2=$ less than half of the adhesive is left on the bracket base;

$3=$ no adhesive is left on the bracket base.

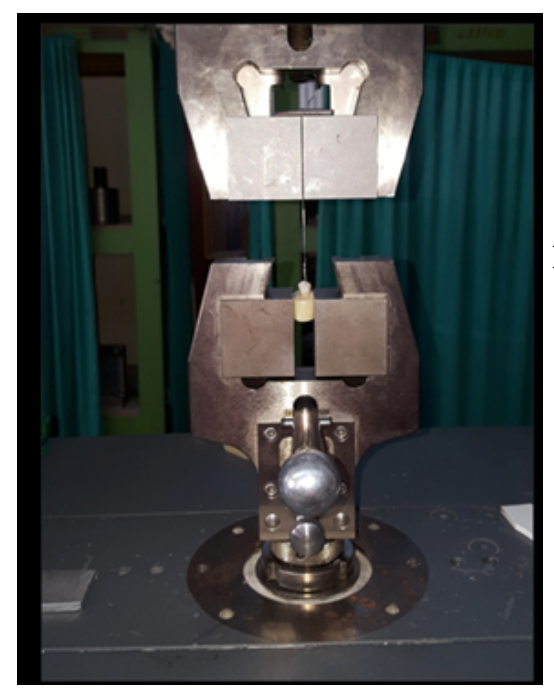

Fig. 1. Sample placed in the Zwick Zoel Z005 machine for testing.

\section{Results and discussions}

The clinician managed to position the APC Flash Free brackets in a shorter amount of time, as it can be observed in table 1. The mean time needed to place the adhesive paste on the uncoated brackets and remove excess adhesive around the bracketwas double in value compared to the Group 1 (table 2).

Table 1

THE AMOUNT OF TIME NEEDED IN ORDER TO BOND EACH BRACKET

\begin{tabular}{|c|c|}
\hline Method & Time [s] \\
\hline APC Flash Free Adhesive System & 19 \\
& 21 \\
& 20 \\
& 21 \\
& 24 \\
\hline Conventional Direct Bonding & 44 \\
& 50 \\
& 41 \\
& 46 \\
& 44 \\
\hline
\end{tabular}

Table 2

MEAN BRACKET BONDING TIME FOR THE TWO GROUPS.

\begin{tabular}{|c|c|c|}
\hline Method & $\begin{array}{c}\text { Mean bracket } \\
\text { bonding time [s] }\end{array}$ & $\begin{array}{c}\text { Standard } \\
\text { deviation [s] }\end{array}$ \\
$\begin{array}{c}\text { APC Flash Free } \\
\text { Adhesive System }\end{array}$ & 21 & 1.8708 \\
$\begin{array}{c}\text { Conventional Direct } \\
\text { Bonding }\end{array}$ & 45 & 3.3166 \\
\hline
\end{tabular}

From the samples utilized in the study, some of them were compromised due to enamel fracture at the cervical limiton the crown. Table 3 presents the force values needed in order to debond each bracket relevant for the study. After 24 hours, the SBS obtained for APC Flash Free brackets is significantly higher than the Clarity Advanced brackets bonded through conventional methods (table 4).

Adhesive remnant index values are presented in table 5. In most cases, more than half of the adhesive remained on the base of the bracket after debonding.
Table 3

SHEAR BOND STRENGTH (SBS) [N]

\begin{tabular}{|r|c|}
\hline Type of brackets & SBS[MPa] \\
\hline APC Flash Free Brackets & 7.93 \\
& 13.62 \\
& 11.36 \\
\hline Uncoated Brackets & 8.52 \\
& 7.31 \\
& 8.86 \\
\hline
\end{tabular}

Table 4

MEAN SBS FOR THE TWO GROUPS [MPa]

\begin{tabular}{|c|c|c|}
\hline Type of brackets & $\begin{array}{c}\text { Mean Shear } \\
\text { Bond Strenght } \\
{[\mathrm{MPa}]}\end{array}$ & $\begin{array}{c}\text { Standard } \\
\text { deviation }\end{array}$ \\
$\begin{array}{c}\text { APC Flash Free } \\
\text { Brackets }\end{array}$ & 10.97 & 2.865 \\
$\begin{array}{c}\text { Uncoated } \\
\text { Brackets }\end{array}$ & 8.23 & 0.8147 \\
\hline
\end{tabular}

Table 5

ADHESIVE REMNANT INDEX VALUES

\begin{tabular}{|c|c|}
\hline Type of brackets & ARI score \\
\hline APC Flash Free Brackets & 1 \\
& 1 \\
& 1 \\
\hline Uncoated Brackets & 1 \\
& 3 \\
& 1 \\
\hline
\end{tabular}

The APC Flash Free System provides a uniform layer of adhesive on the bracket base, in an optimal quantity that eliminates the need to clean around the bracket after positioning. This aspect, combined with the fact that the adhesive is already placed on the bracket, shortens the time needed by the clinician with more than half. Foersch et al [7] had a mean bonding time of $19.5 \mathrm{~s}$ per tooth for the Flash Free system, with a minimum of $14 \mathrm{~s}$ and a maximum of $25 \mathrm{~s}$. Using the conventional technique, the time doubled (i.e., of $40 \mathrm{~s}$ per tooth). Lee and Kanavakis [8] took longer to place the flash free brackets (30.7 s), while they had similar results for the manually adhesive placing group (41.8 s).

All brackets utilized in this study were Clarity Advanced brackets; the difference was in the technique used to apply the adhesive on the base. The Flash Free Group 1 presented higher SBS values after $24 \mathrm{~h}$, with a mean SBS of 10.27 $\mathrm{MPa}$, compared to $8.23 \mathrm{MPa}$ for the uncoated brackets (Group 2). In a study conducted by Cloud etal [9] the mean force used for debonding ceramic coated brackets was 161.7 N. Bakhadher and Talic [10] found lower SBS values for the coated brackets (7.50 MPa), similar to the control, uncoated group (7.36 MPa), with large gaps between the values for different samples (a maximum of $14.66 \mathrm{MPa}$ and a minimum of $2.29 \mathrm{MPa}$ ).

For a better integrity of the enamel, it is preferred for the adhesive to fail at the bracket interface, or eventually inside the body of the adhesive, considering that with the right methods, the remains can be properly cleaned off the tooth surface. Despite this reason, most clinicians prefer to remain less adhesive on the tooth after debonding; this implies less time for cleaning. They also consider that the cleaning procedures can damage the tooth.

$A R I$ values were 1 for most of the samples, with more than half of the adhesive left on the bracket. The type of failure in this situation was an adhesive one, at the toothadhesive interface. Only one sample had an ARI equal to 3 , with all the adhesive left on the enamel surface. A majority of adhesive-enamel failures were also found by 
Ozer et al when debonding APC self ligating brackets, no matter of the choice of the primer utilized [11]. Orthodontic and dental materials characteristics are very important in achieving clinical sucess[12-14].

When cleaning the adhesive around the bracket using the conventional method, the clinician may miss bits of flash. This happened for one sample in this study, when the remaining paste debonded with the bracket. Therefore, compared with the conventional method, the Flash Free system avoids the excess of adhesive around the tooth.

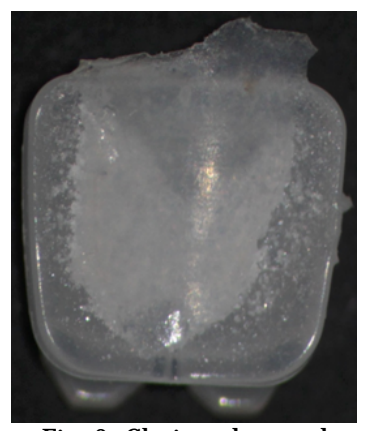

Fig. 2. Clarity advanced bracket after debonding.

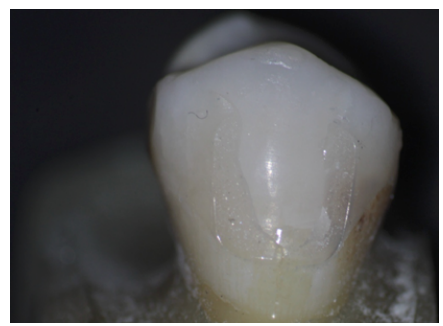

Fig. 3. Tooth surface after bracket debonding (Conventional technique).
Such an excess could change its color in time or needs more cleaning after debonding (figs. 2 and 3 ).

\section{Conclusions}

APC Flash Free System shortens the bonding time by more than half compared to conventional direct bonding of uncoated brackets. Thus, it shortens the chair side time that is needed, leaving for the clinician more time in order to place correctly the bracket, instead of flash cleaning.

Even if the materials included in both groups came from the same company, the flash free technique showed significantly higher SBS values.

ARI scores showed that more than half of the adhesive remained on the brackets base after debonding in the flash free Group 1 and in most samples of the Group 2. This facilitates tooth surface cleaning after debonding, with shorter chair side time and less enamel damage.

Acknowledgements:This research was supported by the Romanian National Authority for Scientific Research, CNDI-UEFISCDI Project PN-III-P2-2.1-PTE-2016-0181 (http://3om-group-optomechatronics.ro/). Cosmin Sinescu also acknowledges the support of the Victor Babes University of Medicine and Pharmacy of Timisoara (Grant PIII-C2PCFI (2015-2016), DENTALOCT).

\section{References}

1. G. V. NEWMAN, Epoxy adhesives for orthodontic attachments: progress report, Am J Orthod 1965, 51(12), 901-912.

2. P. GANGE, The evolution of bonding in orthodontics, Am J Orthod Dentofacial Orthop 2015, 147(4 Suppl), S56-63.

3. U. A. GUZMAN, L. JERROLD, P. S. VIG, A. ABDELKARIM, Comparison of shear bond strength and adhesive remnant index between precoated and conventionally bonded orthodontic brackets, Prog Orthod 2013, 14, 39.

4. A. A. OZ, S. YAZICIOGLU, B. S. AKDENIZ, N. MURAT, S. ARICI, Assesment of the confidence of the adhesive remnant index score with different methods, Turkish J Orthod 2013, 4, 149-153.

5. J. ARTUN, S. BERGLAND, Clinical trials with crystal growth conditioning as an alternative to acid-etch enamel pretreatment. Am J Orthod Dentofacial Orthop 1984, 85, 333-340.

6. S. E. BISHARA, M. E. OLSEN, L. VONWALD, J. R. JAKOBSEN, Comparisons of the debonding characteristics of two innovative ceramic bracket designs, Am J Orthod Dentofacial Orthop 1999, 116(1), 86-92.

7. M. FOERSCH, C. SCHUSTER, R. K. RAHIMI, H. WEHREBEIN, C. JACOBS, A new flash-free orthodontic adhesive system: A first clinical and stereomoscopic study, Angle Orthod 2016, 86, 260-264.

8. M. LEE, G. KANAVAKIS, Comparison of shear bond strength and bonding time of a novel flash-free bonding system, Angle Orthod 2016, 86, 265-270.

9. C. C. CLOUD, T. M. TROJAN, S. M. SULIMAN, D. TANTBIROJN, A. VERSLUIS, Adhesive performance of precoated brackets after expiration, Angle Orthod, 2016, 86, 235-240.

10. W. BAKHADHER, N. F. TALIC, Bond strength and micro-computed tomographic evaluation of pre-coated brackets, Aust Orthod J 2015, 31, 201-207.

11. M. OZER, M. BAYRAM, C. DINCYUREK, F. TOKALAK, Clinical bond failure rates of adhesive precoated self-ligating brackets using a selfetching primer, Angle Orthod 2014, 84, 155-160.

12. SZUHANEK,C., JIANU,R., CIRCIUMARU,L., NEGRUTIU, M.L., SINESCU,C., CLONDA,C.S., SCHILLER,E., POPA, A., GRIGORE, A.,Microstructural Changes in Orthodontic Archwires after Alternative Bending Techniques. Rev.Chim.(Bucharest),67, no. 11,2016,.p.23632364.

13. SZUHANEK, C., GRIGORE, A., Determination of microelements from orthodontic implants by the flame atomic absorption spectroscopy method. Rev.Chim.(Bucharest),66, no.10,2015, p.16001602.

14.GURBAN,C.V., FAUR,A., GOTIA, L.S., LIGHEZAN, R.,TIRZIU, R., CRETU,O., Correlations between Inflammatory Process and Levels of Cytokines in the Gingival Crevicular Fluid in Periodontal Diseases. Romanian Review of Laboratory Medicine2015, Supl.23(1):27-28.

$\overline{\text { Manuscript received: } 21.03 .2018}$ 